\title{
Spine Cancer pT0 TNM Finding v8
}

National Cancer Institute

\section{Source}

National Cancer Institute. Spine Cancer pTo TNM Finding v8. NCI Thesaurus. Code C136584.

Spine cancer without evidence of primary tumor. (from AJCC 8th Ed.) 